\title{
Women's Empowerment, Development Interventions and the Management of Information Flows
}

\author{
Naila Kabeer
}

Abstract This article takes gender inequalities in the distribution of power as its point of departure. Given the widespread evidence of the extent to which women, particularly poor women, have been marginalised in processes by which development policies are designed and implemented, it suggests that explicit attention needs to be given to strengthening women's capacity for voice and action at different stages of the planning cycle. In particular, there are certain 'critical moments' in the life of any intervention when the ideas, values and knowledge of key decision-making actors have a profound impact on how the intervention plays out in practice. The article sets out to develop a theory of change that addresses the issue of women's empowerment. It applies this theory to the critical moments framework. Finally, it draws on case studies of interventions funded by the Bill \& Melinda Gates Foundation to illustrate key lessons for their transformative potential for women's empowerment.

\section{Introduction: aims of the article}

As the Bill \& Melinda Gates Foundation (BMGF) embarks on a programme of agricultural interventions, it recognises the central importance of understanding gendered relations in different contexts if adverse impacts are to be avoided. This article seeks to prove what is hoped will be a useful framework to analyse development interventions from a gender perspective. The framework will be illustrated by two case studies of the BMGF's grantees.

The core belief of the Bill \& Melinda Gates Foundation is that 'all lives - no matter where they are lived - have equal value'. This belief underlies its Gender Impact Strategy for Agricultural Development: 'In the light of this core belief, our vision of success for the gender impact strategy is that women are actively and meaningfully engaged as vital participants in each of our projects...'. Such engagement, according to the strategy, includes women's ability to voice their needs on equal terms with men and to be heard by leaders, policymakers and donors: 'This means special efforts must be made to hear from and listen to voices most marginalised from influential networks and those least likely to have access to functioning markets and services'. This provides the rationale for the discussion in this article.

\section{Women's empowerment and theories of change}

All development interventions operate, either explicitly or implicitly, with theories of change which make 'cause-and-effect' assumptions about the relationship between their activities and intended outcomes. However, because our understanding of social reality is never perfect and because this reality is constantly changing, in both anticipated and unanticipated ways, these assumptions need to be constantly subjected to reality checks.

There is another more serious problem. Theories of change tend to reflect the worldviews of those who formulate these interventions and their understanding of social reality. In a world that is characterised by an unequal distribution of power, this means that the worldviews that underlie development interventions are not only partial and imperfect but likely to be biased. Most often, they are biased against those who do not exercise a great deal of voice or influence in either the

IDS Bulletin Volume 41 Number 6 November 2010 (C) 2010 The Author. Journal compilation (c) Institute of Development Studies Published by Blackwell Publishing Ltd, 9600 Garsington Road, Oxford OX4 2DQ, UK and 350 Main Street, Malden, MA 02148, USA 
formulation of these theories or their translation into interventions. In other words, development interventions do not always promote, or even seek to promote, greater justice in society.

Several decades of research and advocacy have shown that gender is one of the most pervasive examples of social inequality: women's needs, interests and experiences have been systematically excluded, misrepresented or subsumed with those of men within development policy and planning. This research also shows that interventions that seek to challenge gender inequalities can generate major gains - for women themselves, for their families and for society at large. ${ }^{1}$ For these reasons, it is imperative that all development planners are, at the very least, aware of the gender-related impacts of their interventions. However, this article argues for more than simple awareness. It argues for a more proactive empowerment agenda.

\section{A theory of change: gendered analysis of structure and agency}

To understand what is meant by empowerment, it is important to understand what is meant by power. ${ }^{2}$ Power can be conceptualised in terms of people's capacity to make strategic life choices and exercise influence. Empowerment then refers to the processes by which this capacity is acquired by those who have been hitherto denied it. People who exercise a great deal of choice in their lives - to the extent of imposing their choices on others - may be very powerful, but they are not empowered in the sense in which the term is used here because they were not disempowered in the first place. Our theory of change therefore relates to change in power relations. It rests on the intertwined notions of structure, the institutionalised (and hence often invisible) constraints on human action that give rise to durable forms of inequality, and agency, the role of human actors and their efforts to reproduce, modify or transform structural inequality.

\subsection{Gender and the structures of constraint}

Structures are constituted by the rules, norms, beliefs and practices that define social relationships between different groups in a society, assigning greater authority, influence and resources to some groups relative to others and placing them in positions of dominance. As a result, dominant groups are not only better placed to exercise choice over their own lives but also to impose their choices on others. Relations of power take a variety of different forms and define different kinds of inequality. This means that while women may have certain interests in common as a group, they will also share other interests with men from the same class, caste or racial group. Gender-related structures are manifested in the lives of men and women in the form of different kinds of constraints on their actions. We distinguish between three.

Gender-specific constraints: These refer to norms, values and customs which apply to women and men by virtue of their gender. While different societies have their own views about masculinity and femininity, most societies tend to associate men with more valued attributes, abilities and predispositions and women with less valued ones. They also ascribe primary breadwinning roles to men while women are expected to bear the main responsibility for unpaid reproductive work. Societies vary as to the extent they expect women to undertake productive or paid work. For example, women are expected to play an active, and often independent role in farming in subSaharan Africa but have culturally restricted mobility outside the home in South Asia. These constraints help to explain the varying but widely observed asymmetries in the distribution of men and women between sectors, occupations and activities.

Gender-intensified constraints: Associated with the norms and values which define gender identities and roles in different societies are gender inequalities in the distribution of valued resources. These may be defined by the norms and values in question: for instance, patrilineal norms of inheritance place women at a major disadvantage to men in the distribution of land and other property rights. Or they may reflect behavioural responses to the devaluation of women: for instance, discrimination against girls and women in the family distribution of food or access to education. We refer to these as genderintensified constraints to draw attention to the fact that both men and women from low-income households may be disadvantaged in their access to valued resources, but these disadvantages are likely to be exacerbated, by gender. Thus data from different regions of the world shows that while children from poorer wealth quintiles are far more likely to be out of school than children from wealthier quintiles, within each wealth 
quintile, girls are far more likely to be out of school than boys (UN 2010).

Imposed gender constraints: Gender-specific norms and values are generally rooted in the informal institutions of a society. The public spheres of state, market and civil society are purportedly impersonal and gender-neutral institutions. However, when their principal actors behave, consciously or unconsciously, in discriminatory ways, we can think in terms of a third category of imposed gender constraints. For instance, the legal system in many societies upholds customary forms of discrimination against women. In the Democratic Republic of Congo, where women need husbands' permission to start up a business, they run only 18 per cent of small businesses. In neighbouring Rwanda where they do not face such restrictions, they run 41 per cent of businesses (World Bank/FAO/IFAD 2009).

At the same time, it is perfectly possible for social actors, particularly those with authority, to adopt rules, norms and practices which serve to offset and transform long-standing gender inequalities. It has been pointed out, for example, that the adoption of the Convention on the Elimination of Discrimination against Women (CEDAW) by the international community played a major role in empowering women's organisations in Latin America to press for women's land rights in the region's transition to democracy (Deere and Leon 2001).

\subsection{Gender, agency and empowerment}

The concept of agency shifts the focus from social structures to the capacity of different groups to exercise choice and pursue their goals. Theories about agency provide important insights into the perspective of less empowered groups and their struggles to challenge structures and negotiate change. Hirschman's work on 'exit, voice and loyalty' (1970) provides a useful entry point into this discussion. We take 'voice' to refer to the different ways in which women might seek, individually or collectively, to bring about desired forms of change in their lives and relationships. Their capacity for voice is closely related to their ability to 'exit', to either withdraw or withhold cooperation in relation to an unfavourable situation or relationship.

The capacity for voice and exit will in turn depend on the resources that actors are able to mobilise. Such resources may be material in the sense of land, wages, equipment, housing and so on. They may be human both in the narrow sense of 'human capital' for market-related investments and the broader sense of human capabilities needed for critical reflection and analysis. Alternatively, access to resources may be gained through membership of social groups and networks. However, the relevance of these resources for women's voice and exit options does not lie in access alone but also in their strategic potential. Access to resources must promote some degree of security outside the existing arrangements if they are to promote women's empowerment.

The intermediate concept of 'loyalty' has received less attention in the economic literature but it has a particular relevance to the analysis of power. The absence of protest with regards to an existing set of arrangements or the failure to leave can be given a benign interpretation as evidence of genuine satisfaction with these arrangements. There are also more negative interpretations. It may reflect the power of prevailing ideologies about women's inferiority which are internalised by both men and women. Or it may represent the capacity of more powerful groups to use coercive tactics to control the behaviour of others: the widespread incidence of domestic violence is an obvious example in the context of gender relations.

Mainstream theories of power have tended to deal with the power in the negative sense of the power over: the ability of dominant groups to impose their choices on others. By contrast, the processes of change associated with empowerment involve more positive concepts of power. First of all, empowerment has a cognitive dimension: the power within. This involves changes in how women view themselves. Their sense of agency and self-worth is critical if they are to bring about change in other aspects of their lives. Secondly, empowerment has a behavioural dimension reflecting women's increased ability to make strategic choices and exercise influence in the society they live in. This is power in the sense of power to.

Finally, there is a critical relational dimension to empowerment: the power with. Women do not exist in isolation either from each other or from men in their society. Changes in individual 
women are unlikely to go very far in changing structures but women coming together to reflect, to question and to act on their subordinate status can be a powerful force for change. Equally, however, men's attitudes and behaviour towards women in the different spheres of their lives will be critical to the kinds of change women are able to achieve. And men's willingness to ally themselves with women in their struggles for gender justice will provide a powerful reinforcement of the momentum for change.

\subsection{Planning and learning from interventions: 'critical moments' in the life of a project}

This analysis of power highlights the need for a holistic approach to gender equality concerns within the planning process. It draws attention to the active role that development planners can play in providing an enabling environment for women's empowerment. Unfortunately, a large number of development interventions have been, and continue to be, gender blind: by knowingly or unknowingly ignoring the gender-related constraints on women's capacity for agency, they serve to reinforce these constraints. Gender bias has often taken the form of equating women primarily with their reproductive roles and responsibilities or seeking to promote their productive roles without due attention to their reproductive responsibilities.

A gender aware intervention would seek to design its goals and activities on the basis of wellinformed analysis of the existing gender division of roles and responsibilities in particular contexts. In as much as it is based on factual knowledge, it is not difficult to achieve and will help to avoid intensifying existing constraints. Gender transformative interventions go further by seeking to challenge given constraints - although the deep-rooted character of these constraints means that transformation is unlikely to be a one-off event but a gradual and evolving process.

There are no blueprints for social transformation: the diversity of contexts and cultures rules this out. But any intervention that seeks to bring about structural change has to have a theory of change that is grounded in an understanding of local realities and its structure of constraints - and opportunities. Just as women's cognitive capacities are a critical element in the processes involved in their empowerment, so too the cognitive dimension of development interventions - the way interventions 'think', the ideas, values, assumptions and information that shape their practice - is an important determinant of what they are able to achieve.

Bearing this in mind, we can distinguish a number of 'critical moments' in the life cycle of an intervention when the cognitive dimension of actions taken - the ideas, values, assumptions and information drawn on - will have profound implications for its evolution at subsequent stages and hence the kinds of change that it is able to bring about. We will illustrate the significance of these moments with some examples.

The first critical moment is the conceptualisation of an intervention, the formulation of its vision, mission and goals. Interventions may fail to acknowledge gender inequalities in their vision for change, they may ignore women's contribution, or potential contribution, to its goals and objectives or it may overlook the gender-related constraints on women's capacity to participate. For instance, agricultural extension services are frequently built on the assumption noted in the Ethiopian context that 'women don't farm' leading to their widely observed exclusion. Alternatively, they may be focused only on improving the productivity of crops, ignoring the post-harvest handling, processing and storage of crops in which women are more likely to be involved (World Bank/IFPRI 2010).

In Ghana, a land conservation and smallholder rehabilitation project took the decision to recognise multiple types of water users in the water user associations set up in connection so that it went beyond farmers and the need for irrigation to include gardeners, livestock owners and fisherman thus allowing women to be involved (World Bank/FAO/IFAD 2009).

Examples of how gender awareness at the conceptualisation stage can lead to very different responses in different contexts comes from the experience of public works programmes in South Asia (Kabeer 2009). In Bangladesh, where restrictions on women's public mobility made it difficult for them to work alongside men on public works programmes, the response was to set up the Rural Maintenance Programme which specifically targeted women from extremely poor 
households who were willing to undertake waged work. In India, the new National Employment Guarantee Scheme (NREGS), which guarantees 100 days' employment to any rural adult seeking work explicitly included women among the intended beneficiaries and, as we see below, measures to ensure their inclusion.

The second critical moment relates to the translation of goals and objectives into concrete design. The gender-blind conceptualisation of goals and objectives generally translates into gender-blind design. A classic example of this was the Bolivian Social Emergency Fund which was set up to provide temporary employment in the wake of structural adjustment: 99 per cent of its beneficiaries were men (Buvinic 1996). By contrast, the gender-aware conceptualisation of the NREGS was carried over into the design stage: a 30 per cent quota for women, crèches in projects with more than five female participants, equal remuneration rates and proximity of the projects to participants' place of residence. In many states in India, female participation has exceeded the quota (Sudarshan et al. 2010). However, the focus on waged work has meant far lower rates of female participation in those states where women are largely constrained to self-employment.

The third critical moment relates to the implementation of the project, how it is put into practice. An example of the way in which gender blindness at the conceptualisation stage can lead to gender biased implementation comes from the Small Ruminant CRSP (Collaborative Research Support Program) in Peru, the aim of which was to improve management and health practices in relation to livestock. The men of the community were called to, and regularly attended, meetings to discuss improved practices but consistently requested support for cropping systems. It was only two years into the project, when a practice session for castration was set up, that the men stated that women should have attended these meetings since they managed the animals (World Bank/FAO/IFAD 2009).

By contrast, the decision of the International Centre for Tropical Agriculture to convene a panel of female farmers in Rwanda to evaluate its new crop varieties paid significant dividends. The varieties selected by the women had production increases of up to 38 per cent over breeder-selected varieties and outperformed local mixtures 64-89 per cent of the time (Sperling and Scheidegger 1997).

The fourth critical moment relates to monitoring and evaluation efforts. The significance given to gender in such efforts, the methods used, the questions asked and the extent to which these are informed by gender analysis are all important if planners are to learn how an intervention is performing in relation to women's empowerment. It will also help to establish the credibility of organisational claims about their own performance. It is striking to note that, despite the widespread claims about empowerment potential of microfinance, very few microfinance organisations actually include indicators of women's empowerment in their monitoring efforts. Instead they focus largely on loan disbursement and repayment rates and in some cases, on enterprise-related indicators. Where there have been efforts to evaluate the empowerment impact of microfinance, it is evident that this varies considerably between organisations, suggesting that it is not financial services alone that shape what organisations are able to achieve, but the organisational strategy for delivering them (Kabeer 2005).

The fifth and final critical moment concerns the extent to which there are feedback mechanisms which allow information from different stages of the process of implementation to be used to modify practice. It is the presence of these mechanisms that distinguishes learning organisations from those that fail to evolve over time. One example of these feedback mechanisms in operation is BRAC's Targeting the Ultra-Poor programme which was set up in 2003 in response to findings from its own large Research and Evaluation division as well as external studies that the poorest sections of the population, destitute women, often female household heads, were largely excluded from its mainstream microfinance efforts. The effectiveness of the feedback mechanism was strengthened by the fact that these studies not only documented the exclusion of these groups but also the factors which explained their exclusion. This allowed BRAC to design a new programme that took account of these factors (Smillie 2009).

The rest of this article explores the relevance of the 'critical moments' gender analysis in relation 
to two interventions supported by the BMGF, written up as case studies for the Agricultural Learning and Impacts Network (ALINe) project. The first is a case study of a project: the multifunctional platform (MFP) project in Mali (Brody and Davies 2009). The second is the case study of an organisation: PRADAN which uses a livelihoods-based approach to work with women's self-help groups in India (Kabeer 2009).

\section{The MFP case study}

The MFP project has been coordinated by UNDP and the Mali government since the 1990s, and part funded by the BMGF since 2007. The original aim of the project was three-fold: to promote a decentralised, sustainable and socially responsible energy supply; to create employment opportunities, promote productivity and advance women's economic status; and to promote women's wellbeing and empowerment through their control and utilisation of the energy supply and the reduction of the time and energy they spend in heavy work. Women were thus the primary intended beneficiaries of the project from the outset, and their empowerment one of the goals of the project. These empowerment aims have also been reiterated in the BMGFfunded phase of the project.

From its inception, the project involved installing diesel-powered platforms with the capacity to perform functions such as husking rice, grinding and extracting oil from shea nuts - timeconsuming activities that are traditionally rural Malian women's responsibility. In some cases the platforms were also equipped with water and electricity distribution systems. The rationale for installing the machines was to free up time for women to engage in commercial activities, including selling food and other agricultural surpluses. Local people - often men - were trained as technicians to handle technical aspects needed for the smooth running of the MFPs, but the emphasis was on enabling women-headed committees to oversee the management and operation of the machines and to manage any related finances. Community, and specifically women's, participation was promoted by requiring villages to request platforms through their Women's Associations and to contribute towards the cost. Feasibility studies would then select groups of 25 people -20 women and five men - in each village to be trained to work on setting up the platform. Provisions for monitoring social impacts of the MFPs, with some provision for evaluating changes in gender dynamics, were also built into the project design. In addition, the women's committees coordinating the running and financial management of the platforms were strongly encouraged to develop their own capabilities, to work together as a group to identify problems and find solutions, and to perform self-evaluation, facilitated by the project implementers.

Earlier evaluations of the project had identified women's time and energy savings, increases in agricultural production and surplus, diversification into higher value products and enhancement of women's income as some of their key impacts. However, they did not generally touch directly on women's empowerment. This was discussed more explicitly as part of the field visit carried out by Brody and Davies (2009). Their interviews with project staff and women beneficiaries noted evidence of women's time gains, increased financial knowledge, improvement in family planning and increased education of girls who no longer had to help their mothers at home.

Women themselves also recounted benefits in terms of their wellbeing, related to time for their families and productive activities, and reduced conflicts at home. They also reported that they were more respected in the village than previously and had a bigger role to play in decision-making at the community level. However, Brody and Davies did not find any conclusive evidence that the project had contributed to changing power relations in the domestic domain. Nothing in what was reported by either project staff or the women themselves suggested that the economic gains that women had made and their greater public role had been significant enough to have an impact on some of the more resilient manifestations of gender inequality within the household, including domestic violence and female genital mutilation. This is not to say that such changes are not happening - but they did not emerge during the fieldwork and there is not currently a strategy in place to address these issues or to monitor possible changes in light of the MFP interventions.

Additionally, even though women are beginning to gain more public respect and voice in villages participating in the projects, it appeared that 
there had been few or no changes in the gendered division of labour. In fact, in many ways the project contributed to reinforcing women's specific roles: the fact that the gains in time would enable women to perform their traditional tasks more effectively was reiterated by most of the stakeholders we interviewed.

To conclude, this was in many ways a successful project. Women had been a key focus in the conceptualisation phase. Their time burdens had been identified as a major constraint on their productivity and leisure and the project was designed to directly address this. In addition, efforts had been made during the implementation stage to ensure that they played a leading role in managing the platforms. The evaluations suggested that the project had achieved some of the impacts it set out to achieve. Yet given that the women's empowerment was one of the explicit objectives of the project, why did it appear to have so little impact on intra-household relations?

In terms of our critical moments framework, the explanation may lie in the failure to address gender inequality as an issue of power at any stage in the project cycle. The conceptualisation of the project had been largely in terms of easing women's time burdens, giving women visibility in project-initiated committees and providing them with technical training. A great deal of attention had been paid to changes in women's lives that centred around the effective use of the platform. But there had been far less attention to what happened in other arenas of women's lives. While provision had been made to carry out gender training for staff as part of project design, this had not materialised in the implementation phase. And the training provided to women was confined largely to technical issues. The absence of any analysis of power or attention to women's rights at the first critical moment was thus reproduced in subsequent critical moments of the project cycle.

\section{The PRADAN case study}

PRADAN was set up in 1983 in order to support the livelihoods of poor farmers in the rainfed hilly areas of the poorer regions of India which had been largely bypassed by the Green

Revolution technology. PRADAN recognises that the poorest households in rural India are caught in a 'poverty trap' and require livelihood support to enable them to grow out of it. It focused on women from the outset because they were seen to be more responsible than men about family welfare and also because they were perceived to be the most marginalised members of already marginalised groups.

PRADAN is one of the pioneers of the Self-Help Group (SHG) approach, widely prevalent in India, where women come together in groups of around 20-30, meet regularly, save a certain amount into a common fund until they have enough capital to make small interest-bearing loans to each other or to others in the village. Groups are then linked to bank loans under the Government of India's SHG-Bank Linkage programme. In addition, group members who are interested in further strengthening their livelihoods, and have the necessary assets, participate in specific programmes which provide them with training and marketing support. While there is considerable scope for discussion of organisational performance among the staff, its computerised monitoring system is limited to tracking information on women's savings and credit activities.

An evaluation study carried out by the author (Kabeer and Noponen 2005) was therefore one of the first opportunities for the organisation to gain a systematic overview of its impacts. The study found that the organisation had considerable success in its livelihoods promotion efforts (diversification of activities, asset accumulation, etc.) It also found positive impacts on women's public participation and livelihood skills (knowing how to sign their names and calculate interest rates). However, the evidence was far more mixed in relation to impacts on intra-household power relations including women's role in strategic areas of decisionmaking and domestic violence. While the study found positive impacts on some of these, on others, impact was insignificant.

However, one important additional finding was that women who had attended PRADAN's livelihoods programmes were far more likely to report positive impacts on intra-household relations than those who had not. While these programmes were focused on livelihood issues, they took a very participatory approach, encouraging women to reflect on their current livelihood options and to envisage what the 
future might look like. It may have been the intense social interactions involved in these group exercises as well as the attention to cognitive change that explained the additional difference that the livelihoods programmes made in women's lives.

The impact study fed into ongoing debates within PRADAN. Many of its own staff had already expressed the view that the organisation needed to combine its attention to sustainable livelihoods and poverty reduction with greater attention to the empowerment of self-help group members to enable them to stand up to instances of injustice in their relations with others and to deal with those in authority.

In terms of the critical moments framework outlined earlier, we find that women were central in the conceptualisation of the programme but in terms that stressed their instrumentality (responsible mothers) and victimhood (most marginal of the marginal). However, the self-help group model with its stress on promoting women's capacity to save and manage their own financial affairs combined with participatory forms of training appeared to have achieved cognitive and behavioural changes that went beyond this early conceptualisation. Despite the lack of a formal monitoring system, the flat structure of the organisation enabled lessons from the field to be communicated and discussed across the organisation, promoting a culture of learning. This explains why questions about the limits of a livelihood focus were already being raised within the organisation before the external evaluation helped to crystallise these concerns.

PRADAN is currently engaged in a strategic review of its strategies to adapt them to new challenges and opportunities. Steps have been taken to integrate gender analysis into its staff training programme. It has also embarked on a radical new approach towards its SHG programme with a view to transforming the groups into a force for transformative change within the community.

\section{Conclusion}

This article has sought to incorporate a concern with women's empowerment into the management of information and ideas across the planning cycle. The theory of change that underpins its approach stresses the critical importance of the cognitive dimension, and hence of human agency, in shaping how an intervention unfolds from conceptualisation to final outcomes. The ideas, information, vision and commitment of the different actors that conceptualise, design, implement, evaluate and learn from different stages of an intervention will make an enormous difference to what the intervention is able to achieve.

In terms of the 'critical moments' framework used to organise the analysis of development interventions, it is clear that the ideal approach would be to ensure that concerns with gender equality are present in each of these moments, but that it is important to get it sufficiently right at the conceptualisation stage to ensure that there is follow-through at other stages. While gender equality concerns can be introduced belatedly, the costs of getting it wrong are harder to rectify further into the life of a project. Our analysis also shows that how gender is conceptualised within a programme will also have implications for its outcomes: is it seen purely as a matter of efficiency and instrumentality or is it conceptualised in terms of social justice?

At the same time, the unpredictability of social reality means that integrating these concerns early in the life of an intervention does not fully determine its outcomes. The role of human agency also matters in its design and implementation. While PRADAN did not incorporate a concern with women's empowerment into its early vision of social change, its emphasis on promoting women's selfreliance and the participatory nature of the training it provides its members did contribute to this outcome. It is this emphasis on participation that seems to be missing from the more technically driven MFP project. 


\section{Notes}

* This article is partly based on findings from field visits carried out as part of the ALINe programme. Alyson Brody (Senior Gender Convenor at IDS) and Caroline Davies (former ALINe Coordinator) carried out the fieldwork on the Multifunctional Platform project in Mali. Their report traces a historical trajectory of the project, including the phase that has been funded by the Bill \& Melinda Gates Foundation since 2007. It draws on available information over the course of the project as well as on interviews with various key

\section{References}

Brody, A. and Davies, C. (2009) ALINe Field Report on Visit to the UNDP Multifunctional Platforms Project (Reducing Poverty and Empowering Women), Mali, Brighton: ALINe IDS

Buvinic, M. (1996) Promoting Employment Among the Urban Poor in Latin America and the Caribbean: A Gender Analysis, Issues in Development Discussion Paper 12, Geneva: International Labour Office

Deere, C. and Leon, M. (2001) Empowering Women: Land and Property Rights in Latin America, Pittsburgh: University of Pittsburgh

Hirschman, A.O. (1970) Exit, Voice and Loyalty: Responses to Decline in Firms, Organisations and States, Cambridge, MA: Harvard University Press

Kabeer, N. (2009) Building Livelihoods and Empowering Women: A Case Study of PRADAN, India, Brighton: ALINe IDS

Kabeer, N. (2008) Gender, Social Protection and the Informal Economy, New Delhi: Routledge

Kabeer, N. (2005) 'Direct Social Impacts of Microfinance' and 'Wider Impacts of Microfinance: Social Exclusion and Gitizenship', in J. Copestake, M. Greeley, S. Johnson, N. Kabeer and A. Simanowitz (2005), Money with a Mission: Vol. 1. Microfinance and Poverty Reduction, London: ITDG Publications

Kabeer, N. (2001) 'Resources, Agency, Achievements: Reflections on the Measurement of Women's Empowerment', Discussing Women's Empowerment - Theory and stakeholders in Mali conducted in 2009. Naila Kabeer carried out fieldwork in 2009 for the case study on PRADAN in India. Her report traces the historical trajectory of the project since its inception. It draws on project documents, interviews with staff and SHG members and her own earlier study of PRADAN. Many thanks are also due to Jennie Dey Pricyk for comments and Linnet Taylor for editorial assistance.

1 See UN-DAW (2009).

2 This analysis draws on a more detailed discussion in Kabeer (2001 and 2008).

Practice, Stockholm: Swedish International Development Cooperation Agency (Sida)

Kabeer, N. and Noponen, H. (2005) Social and Economic Impacts of PRADAN's Self-Help Group Microfinance and Livelihoods Promotion: Analysis from Jharkhand, India, Imp-act Working Paper 11, Brighton: IDS, http://www2.ids.ac.uk/ impact/publications/working_papers.html (accessed 7 September 2010)

Smillie, I. (2009) Freedom from Want. The Remarkable Success Story of BRAC, the Global Grassroots Organisation that is Winning the War Against Poverty, Sterling VA: Kumarian Press Sperling, L. and Scheidegger, U. (1997) Results, Methods and Institutional Issues in Participatory Selection: The Case of Beans in Rwanda, Ottawa, Canada: International Development Research Centre, http://archive.idrc.ca/library/ document/104582/sperling.html (accessed 17 August 2010)

Sudarshan, R.M.; Bhattacharya, R. and Fernandez, G. (2010) 'Women's Participation in the NREGA: Some Observations from Fieldwork in Himachal Pradesh, Kerala and Rajasthan', IDS Bulletin 41.4: 77-83

UN (2010) The Millennium Development Goals Report 2010, 23 June

UN-DAW (2009) World Survey of Women in Development, New York: United Nations

World Bank/FAO/IFAD (2009) Gender in Agriculture Source Book, Washington DC: World Bank

World Bank/IFPRI (2010) Gender and Governance in Rural Services, Washington DC: World Bank 